\title{
MET NIEUWE OGEN
}

\section{DE HISTORISCHE FOTOCOLLECTIE VAN HET INSTITUUT KERN ONTSLOTEN}

DE VERENIGING INSTITUUT Kern in Leiden heeft in de ruim 75 jaar van haar bestaan een collectie van ca. 70.000 foto's samengebracht met betrekking tot de kunst en archeologie van Zuid- en Zuidoost-Azië. Het betreft sepiagetinte en zwart-wit foto's die de architectuur, beeldhouw- en schilderkunst, de numismatiek, zegelkunde en de materiële cultuur illustreren. Zo'n 30.000 foto's hebben een opnamedatum van voor 1940 en worden als 'historisch' betiteld. Het grootste deel van de overige 40.000 foto's was voorheen ondergebracht in de Bibliotheek Aziatische Kunst Amsterdam (BAKA); zij maken sinds 1997 deel uit van de Kern-collectie. Deze foto's zijn van recenter datum en dekken de Aziatische kunst zowel geografisch als chronologisch.

HOEWEL AL DEZE foto's in het verleden enkel en alleen verzameld zijn om hun documentatiewaarde voor onderwijs en onderzoek, zijn er door de decennia heen heel wat waarden bijgekomen, zodat wij, anno 2003, de collectie met duidelijk andere ogen bezien. Zo tonen de foto's ons bouwwerken en objecten in een staat en een context die niet de huidige is, waarmee ze tevens tot waardevolle historische documenten worden. Delen van de collectie zijn tot Cultureel Erfgoed verheven en de geschiedenis van de fotografie blijkt binnen de collectie uitstekend te volgen.

Ik nodig u uit kennis te nemen van deze collectie, een vase of plenty van beelden en digitale images. Een artikel dus over Aziatische kunst en archeologie, verval en restauraties, fototechnieken en vroege fotografen, maar ook over de op conservering en digitale ontsluiting gerichte zorg voor dit unieke stukje fotografisch erfgoed.

\section{De 'fotohunters' Vogel en Krom}

HOE KOMT EEN instituut aan 30.000 historische foto's en wat was het idee achter de collectievorming? Tijd voor de introductie van twee grootheden uit het Leids universitaire verleden: prof.dr. J.Ph. Vogel (1871-1958, leerstoel Sanskrit, self-made archeoloog) en prof.dr. N.J. Krom (1883-1945, leerstoel 'Archaeologie en Oude Geschiedenis van Nederlandsch-Indië'). Beide heren hadden voor hun aanstelling bij de Leidse Universiteit een uiterst arbeidzaam archeologisch leven achter zich. Prof. Vogel gaf vanuit Lahore tussen 19011913 leiding aan de Northern Circle van de Archaeological Survey of India (ASI) en prof. Krom werd in 1913, na eerst de Oudheidkundige Commissie voor Java en Madoera te hebben geleid, de eerste 'Chef' Oudheidkundige Dienst in Nederlandsch-Indië (O.D).

Fotografie was een deel van hun leven, als eindverantwoordelijken binnen hun organisatie voor de fotografische vastlegging in situ, bij opgravingen en - na een vorm van transport - in de musea. Werkend in het heden van rond ccess 
1900 , ontstond bij hen de behoefte om zoveel mogelijk beeldmateriaal te verzamelen uit een tijd die toen al duidelijk 'verleden' was.

Vogel en Krom kenden elkaar, en elkaars vakgebied goed. In 1905 werd Vogel uitgenodigd te solliciteren naar de functie van voorzitter van de Oudheidkundige Commissie voor Java en Madoera, een post waarvoor hij, naar volle tevredenheid werkend in Lahore, bedankte. ${ }^{2}$ Enkele jaren later zal Krom de post aanvaarden. Ook bezocht Krom in 1910 Vogel in India ${ }^{3}$ om een indruk te krijgen van de Indian Survey als organisatie en de veel geroemde Annual Report-serie, archeologische jaarverslagen waarin gestreefd werd naar een goede verslaglegging en fotografische documentatie van opgravingen.

Eenmaal terug in Nederland, hebben vakenthousiasme en cultuurfascinatie geleid tot hun gezamenlijke oprichting van de Vereniging Instituut Kern (1925), het eerste universitaire instituut in Nederland voor de archeologie van Zuid- en Zuidoost-Azië. Het richtte zich nadrukkelijk op het hele Indische cultuurgebied, waaronder destijds werd verstaan: Voor- of BritsIndië (Zuid-Azië), Achter-Indië (Thailand, Myanmar, Cambodja) en Nederlandsch-Indië (Indonesië). Naar hun mening moest het instituut naast boek- en plaatwerken, munten, realia, afdrukken van inscripties en afgietsels, kunnen beschikken over een zeer ruime fotocollectie. Geen onderzoek en vakkundig onderwijs zonder een groot reservoir van beeldmateriaal! Een dergelijke opzet zou uniek zijn in de wereld. Het gaf Nederland de mogelijkheid "eens ergens in voor te gaan, in plaats van te volgen". We zullen zien hoe het instituut erin geslaagd is dit vereiste beeldreservoir te vullen.

\section{Fotografie in Azië}

HOEWEL DE BELANGRIJKSTE fotografische uitvindingen in Europa werden gedaan, heeft het medium fotografie zich ook in Azië snel verspreid. Gekoloniseerde landen hadden in deze een voorsprong: de Europese ontwikkelingen blijken er op de voet gevolgd. Camera's, glasnegatieven en vereiste papiersoorten bleken na marktintroductie vaak binnen het jaar voorhanden. Zo kon de firma Thacker, Spink \& Co. in Calcutta, al in januari 1840 de eerste daguerreotypiecamera's leveren en dat, terwijl de openbare bekendmaking van het fotografische procédé van de Fransman Louis J.M. Daguerre pas in september 1839 had plaatsgevonden.

Een groot aanbod van fotografische artikelen getuigt van een grote vraag. Het kunnen weergeven 'naar de natuur' bleek een grote aantrekkingskracht te hebben op ieder die beschikte over de vereiste financiële middelen en voldoende vrije tijd om met het middel te experimenteren. Fotografie werd tot een gewilde bezigheid met een moderne uitstraling.

IN DE AFGELOPEN jaren is er veel aandacht geweest voor deze formatieve fase in de Azië-fotografie. Advertenties in de oude dagbladen werden systematisch nagelopen, ${ }^{4}$ directories geverifieerd en jaargangen van Photographic Societies geanalyseerd. Als resultaat hiervan verschenen er schitterende monografieën en tentoonstellingscatalogi over het werk van een aantal belangrijke fotografen en fotografische firma's (zie literatuur). Ook heeft de Internetontsluiting van een aantal belangrijke fotobezittende instellingen fors bijgedragen aan het onder de aandacht brengen van de fotografie bij een breed publiek. ${ }^{5}$ De vroege fotografie in Indonesië en India heeft daarbij veel aandacht 
WIE WAREN DEZE eerste fotografen in Azië? Kort getypeerd: experimenterende Europeanen. In de door de Britten gekoloniseerde gebieden waren het vooral mensen uit het militaire apparaat, zoals de Captains Gill, Tripe, Lyon en Biggs, en niet te vergeten: Major Cole. Ook opvallend veel mensen uit de medische hoek: dr. Pigou, de chirurg McCosh en dr. Murray, directeur van de Geneeskunde opleiding in Agra.

Op Java blijken meerdere fotografen afkomstig uit de artistieke hoek. Het waren van origine veelal lithografen, schilders (Lecouteux, Kinsbergen, Beynon, Camerik) of tekenaars (Veen) die het nieuwe medium incorporeerden in hun activiteiten om een bredere bestaansbasis te hebben.

Zowel het Brits- als het Nederlands-Indische koloniale apparaat blijkt zeer geinteresseerd in al deze activiteiten. Hun eerste stappen in fotografische richting zetten ze dan ook door relevante foto's aan te kopen of om projecten van grotere omvang mee te financieren, zoals bij de vastlegging van de Boroboedoer in 58 daguerreotypieën door Adolph Schaefer in 1845. Met hun semi-wetenschappelijke inspanningen maar professionele resultaten leggen deze vroege fotografen - nog voor de opkomst van grote commerciële fotografische firma's als Bourne \& Shepherd, Johnston \& Hoffman, Burke, Woodbury \& Page - de basis voor de opkomst van de opdrachtfotografie. Zo maakt Linnaeus Tripe in 1855 deel uit van de missie naar het hof van Ava (Myanmar) en mag de decor-, portetschilder en fotograaf Isidore Kinsbergen in 1862 in het 'belang van de wetenschap' mee op een missie naar het hof van Siam en zal hij later Gouverneur Baron L.A.J.W. Sloet van de Beele begeleiden op zijn gouvernementsreizen over Java, Madura en Bali.

Deze fotografie 'in opdracht van' zal van een aanvankelijk algemene vorm van documentatie, uitgroeien tot een specifieke fotografische vastlegging, gevoed vanuit de verschillende wetenschappelijke disciplines, zoals de natuur- en aardwetenschappen (Junghuhn; Veth), de antropologie (Nieuwenhuis) of de archeologie (Kinsbergen, Cephas, Groneman). Vaak hebben deze gerichte exploraties een expeditiekarakter. We zoomen in op van Kinsbergen.

\section{De subcollectie Kinsbergen}

DE OUDSTE FOTO's van de Kern-collectie zijn gemaakt door Isidore van Kinsbergen (1821-1905), een artistiek veelzijdige Zuid-Nederlander (Brugge) die sinds 1851 in Batavia verblijft en zich naast zijn werk als portrettist en eerste decorschilder van de Bataviase schouwburg, toelegt op het nieuwe, financieel lucratieve medium fotografie. Zijn archeologische fotoseries Oudheden van Java (1863-1867) en Boro-boedoer (1873) zijn een mooi voorbeeld van archeologische opdrachtfotografie in het pre-archeologischedienst-stadium in Nederlands-Indië. De series krijgen dan ook de subtitel: op "last van de Nederlandsch-Indische regering, onder toezigt van het Bataviaasch Genootschap van Kunsten en Wetenschappen" mee. De Oudheden van Java, de fotografische vastlegging in 332 prints van antiquiteiten als inscripties, rituele voorwerpen, boeddhistische en hindoeïstische sculptuur en vele candis, betekent de doorbraak voor het medium fotografie binnen de archeologie en de terugdringing van de rol van de tekenkunst daarin (afb.1). Oudheden van Java bleek een opdracht van kaliber. Van Kinsbergen werkte volgens het in 1851 gepubliceerde procédé van Frederick Scott Archer: het 


\section{Afbeelding 1}

1864-1865. Stele met een vierarmige voorstelling van de hindoegod Vishnu, Centraal Java, ge eeuw.

Oudheden van Java serie no. 153 ,

Albumineprint, $32 \times 24 \mathrm{~cm}$.,

Isidore van Kinsbergen

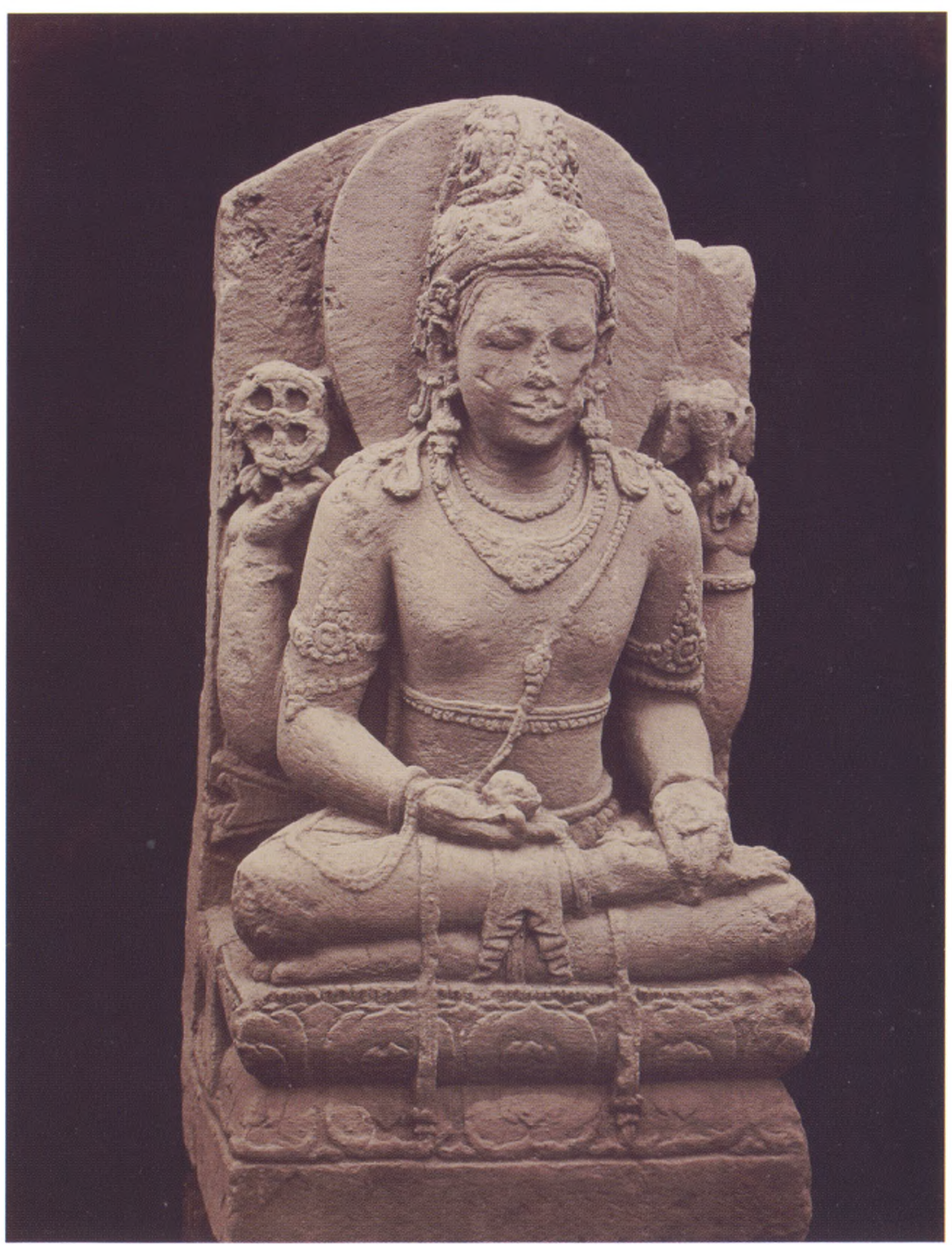

collodium negatief. Hierbij vormde een glazen plaat de negatiefdrager, die voor gebruik voorzien werd van een vloeibaar preparaat, bestaande uit collodium (functie: bindmiddel) en zilverjodide (functie: lichtgevoeligheid). Een dergelijk negatief was maar korte tijd bruikbaar: zodra de emulsie op de glasplaat opdroogde, verdween de gevoeligheid! Dus nat en wel werden de platen in de camera geplaatst, belicht (1-60 seconden), aansluitend in daglicht ontwikkeld en vervolgens gefixeerd. Er werd afgedrukt op een albumine (kippeneiwit) gecoate papiersoort die eveneens voor gebruik nog lichtgevoelig gemaakt moest worden middels een applicatie van zilverchloride. Deze combinatie van de 'natte plaat' als negatiefdrager met de albumine print als eindresultaat zal - hoewel bewerkelijk - de standaard werkwijze worden voor de meeste fotografen tot ca. 1880.

Van Kinsbergen heeft maar liefst 5 seizoenen nodig gehad om de serie te kunnen maken, ${ }^{6}$ zich daarbij geleidelijk verplaatsend van West- naar OostJava. Uit de reisverslagen van beroemde fotografen als Samuel Bourne ${ }^{7}$ (1834-1912, in India actief tussen 1863 en 1870) en Walter Woodbury ${ }^{8}$ ree access 


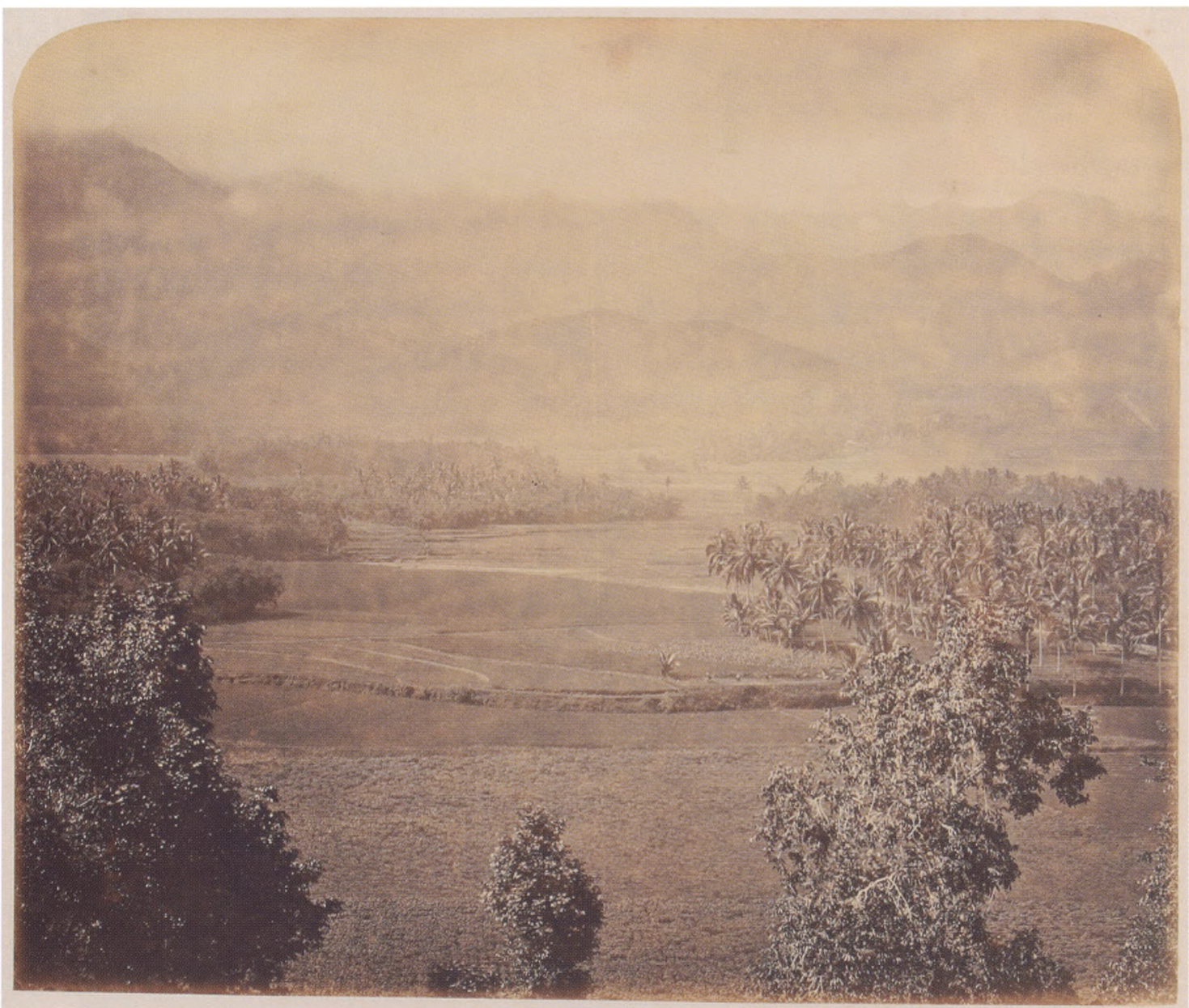

Afbeelding 2 1873. Landschap gefotografeerd vanaf de top van Candi Boroboedoer in zuidwestelijke richting met de berg Menorah in de verte, Kedu plateau, Centraal lava. Borobudur serie no 64, Albumineprint, $24 \times 29 \mathrm{~cm}$., Isidore van Kinsbergen
(1834-1885) blijkt, hoe moeizaam het was om in het treinloze tijdperk, buiten het directe bereik van de eigen studio, fotografische opnamen te maken. Een dergelijke expeditie vereiste al snel een 30-tal lastdieren of dragers voor het transport van de camera's, de kisten met glasplaten, de vele chemicaliën, de tenten, het beddengoed en het proviand. Daarnaast was er voor van Kinsbergen het probleem van het geschikt maken van de sites voor de fotografie. In de praktijk betekende dit: tijdrovende schoonmaakwerkzaamheden, het nemen van drainagemaatregelen om gedeeltelijk ondergelopen bouwwerken toch goed op de plaat te kunnen vastleggen en het bouwen van stellages voor het juiste fotografische standpunt. Geen wonder dat de productiekosten voor Oudheden van Java $f$ 37.500,- bedroegen! Geen wonder ook, dat de verwachtingen hoog gespannen waren. Al klinkt er her en der een dissonant, zijn uiteindelijke serie dwingt (een) respect(volle toon) af: "Met onverdeelde belangstelling en eenparige ingenomenheid worden de photographien van den Heer van Kinsbergen bezichtigd. Slechts ééne stem doet zich hooren over de voortreffelijke uitvoering van den voor den Heer van Kinsbergen ondernomen arbeid, waardoor eene onschatbare baat is verkregen voor wetenschap en kunst, want herkent men in de wijze waarop de voorwerpen zijn afgebeeld onmiddellijk de hand van den ervaren kunstenaar, aan den anderen kant is aan de beoefenaars van Indië's $\boldsymbol{S}_{\text {a }}$ free access 


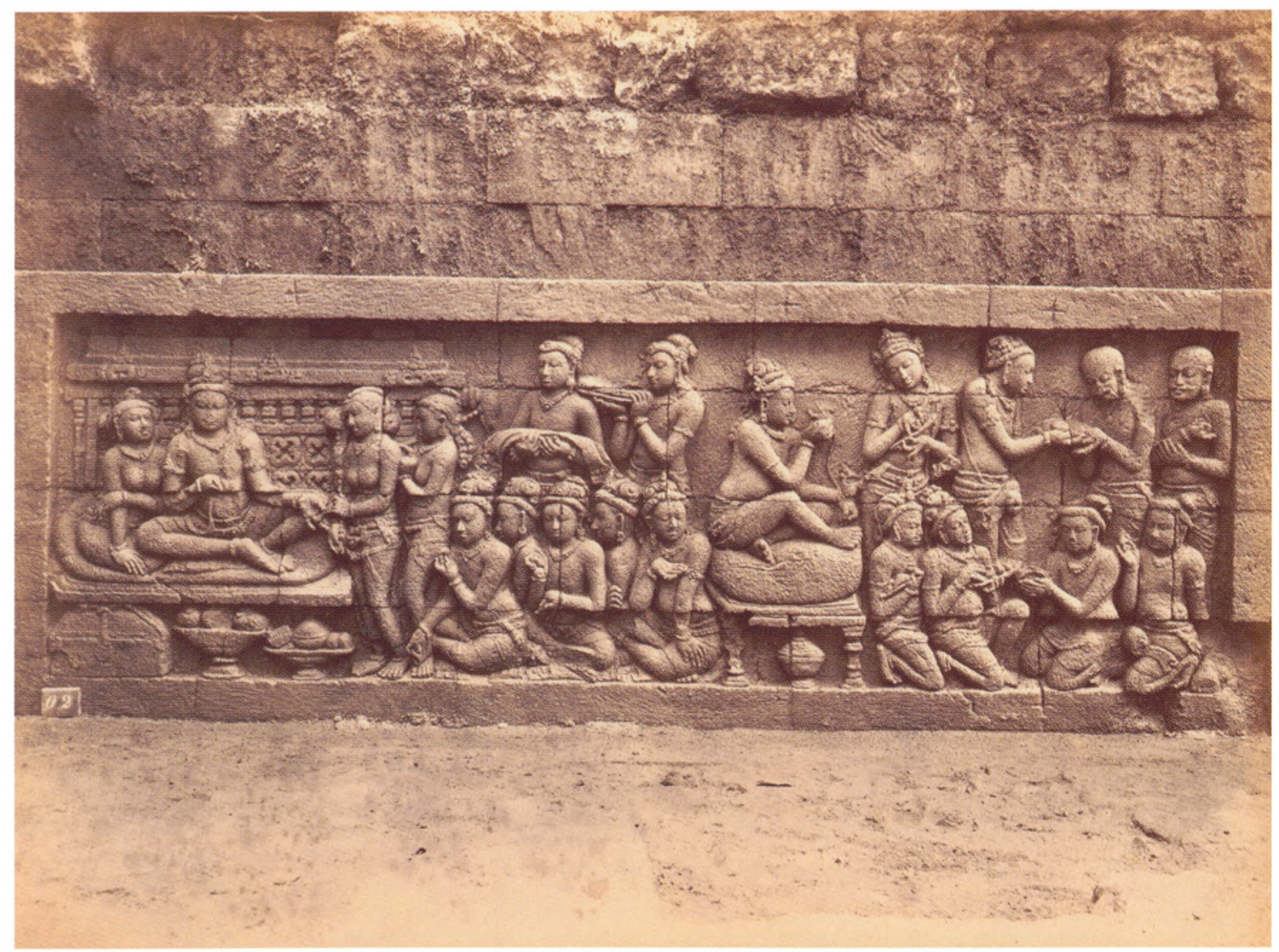

Afbeelding 3

1890-1891. Foto O 2 uit de 'Boro-boedoer verborgen voet'-serie. Een ongeidentificeerd, verhalend reliëf met links een in een paviljoen gezeten paar dat diverse giften krijgt aangeboden en rechts een scène waarbij de schenking van gaven centraal staat, Kedu Plateau, Centraal Java, 8e-ge eeuw. Albumineprint, $16 \times 21,5 \mathrm{~cm}$., Kassian Cephas geschiedenis en oudheidkunde een studiebron van onschatbare waarde geopend, die vroeger zoo goed als gesloten was." 9

Door allerlei technische problemen is de serie nooit, zoals gepland, in drukvorm uitgegeven en is de totale verspreiding daardoor beperkt gebleven: buiten het exemplaar voor Z.M. de Koning, is er slechts een 15-tal wetenschappelijke instellingen, dat de albumineprints - verdeeld over 5 portfolio's bezit. Ook de losse verkoop destijds lijkt beperkt gebleven. Toch blijken het zijn foto's te zijn die door wetenschappers en uitgevers nog vele decennia worden gebruikt en daarmee aan de basis staan van onze beeldvorming van de Javaanse kunst. Van Kinsbergens tweede archeologische serie, eind 1873 vervaardigd, is de zogenaamde Boro-boedoer serie, geheel gewijd aan het in de Kedu gelegen boeddhistische wereldmonument uit de 8e-9e eeuw na Chr. De omvang van het bouwwerk zelf, de beperkte tijd, de kwantiteit van de reliëfs en de onmogelijkheid om het met de camera's van die tijd gemakkelijk te kunnen benaderen, hebben de serie getalsmatig doen blijven steken op 42 foto's. Waar het aantal teleurstelde, deed de kwaliteit dat niet. Met name de opnames van reliëfs dwingen door de combinatie van scherpte en lichtval groot respect af. Afbeelding 2 toont de enige landschapsfoto uit de Boroboedoer-serie. 
Niet geheel chronologisch, maar wel inhoudelijk in lijn, volgt hierop het werk van Kassian Cephas (1844-1912), een commercieel, vanuit Yogyakarta opererende Javaanse fotograaf die niet alleen in meerdere series het hofleven van Yogyakarta heeft vastgelegd, maar ook enkele archeologische series heeft gemaakt (zie literatuur). Hij fotografeert zowel in opdracht van de Archaeologische Vereniging Jogyakarta als voor het Bataviaasch Genootschap voor Kunsten en Wetenschappen in Batavia.

De Kern-collectie omvat de serie over het Loro Jonggrang tempel-complex te Prambanam (1889-1890; 62 foto's) en de beroemde Boro-boedoer bedolven voet serie. Deze serie werd tussen september 1890 en maart 1891 gemaakt, waarbij Cephas op systematische wijze de 160 recentelijk door ingenieur IJzerman 'herontdekte' reliëfs aan de voet van de Boroboedoer vastlegde. De plintreliëfs ( $\mathrm{afb}$. 3) blijken na ontgraving buitengewoon gaaf, waardoor verondersteld wordt dat het zicht op de gedecoreerde plint vrij gauw na de voltooiing van de Boroboedoer werd opgegeven in ruil voor een zware steunbiedende aarden laag. De uniciteit van de foto's is gelegen in het feit dat deze reliëfs hierna nooit meer gefotografeerd zijn; dit vanwege het feit dat de plint van de Boroboedoer na voltooiing van de fotografische vastlegging, opnieuw - op vier reliëfs na - werd afgedekt, vanwege de vereiste steun voor het monument als totaal.

Ook heeft het instituut nog 35 losse Boroboedoerfoto's van Cephas en enkele tientallen foto's van kunstvoorwerpen en diverse Indonesische candis.

Nagenoeg alle opnamen zijn afgedrukt op albumine-papier. Cephas maakte daarbij niet langer gebruik van de 'natte' collodiumplaat maar van 'droge' gelatineplaten: glazen negatiefplaten die al voorzien waren van een lichtgevoelige gelatinebroomzilveremulsie.

\section{India's vroege Survey-fotografie}

TIJD OM TERUG te keren naar de vroege fotografie van het oude ongedeelde India. Aan het werk van beroemde India-fotografen als Felice Beato, Samuel Bourne, John Burke of John Murray gaat onze collectie helaas voorbij. Wel mogen we rond 1870 de draad opnemen bij de vroege 'Survey-fotografie', die goed vertegenwoordigd is in de Kern-collectie.

In tegenstelling tot Nederlands-Indië, had Brits-Indië al in 1861 een Archaeological Survey, die vanwege de grootte van het subcontinent was opgedeeld in verschillende Circles. ${ }^{10}$ De fotografie als middel tot vastlegging kon hier vrij snel worden geïncorporeerd dankzij de vele met het medium experimenterende military servants en vakkundige Indiërs als Joseph Beglar en Lala Deen Dayal.

De archeologische fotografie was toen nog uniek genoeg om goed geadministreerd te worden. Zo geeft het Indian Museum in Calcutta, tot 1900 de centrale bewaarplaats voor alle Survey-negatieven binnen India, als sluitstuk van haar archiverende taak een negatievenlijst uit, waarin korte eenregelige beschrijvingen zijn opgenomen met relevante informatie als: fotograaf, locatie, objectaanduiding, glasplaat- en boxnummer en een eventuele literatuurverwijzing. ${ }^{11}$ Een drietal voorbeelden:

Afbeelding 4 toont ons de grote Moskee in Agra (Jami of Badshahi Mosque), een onder Shah Jahan in 1648 gereedgekomen Mughalbouwwerk Een $_{26}$ foto $_{3}$ die alleen maar indrukwekkender wordt, naarmate hij groter wordt via free access 


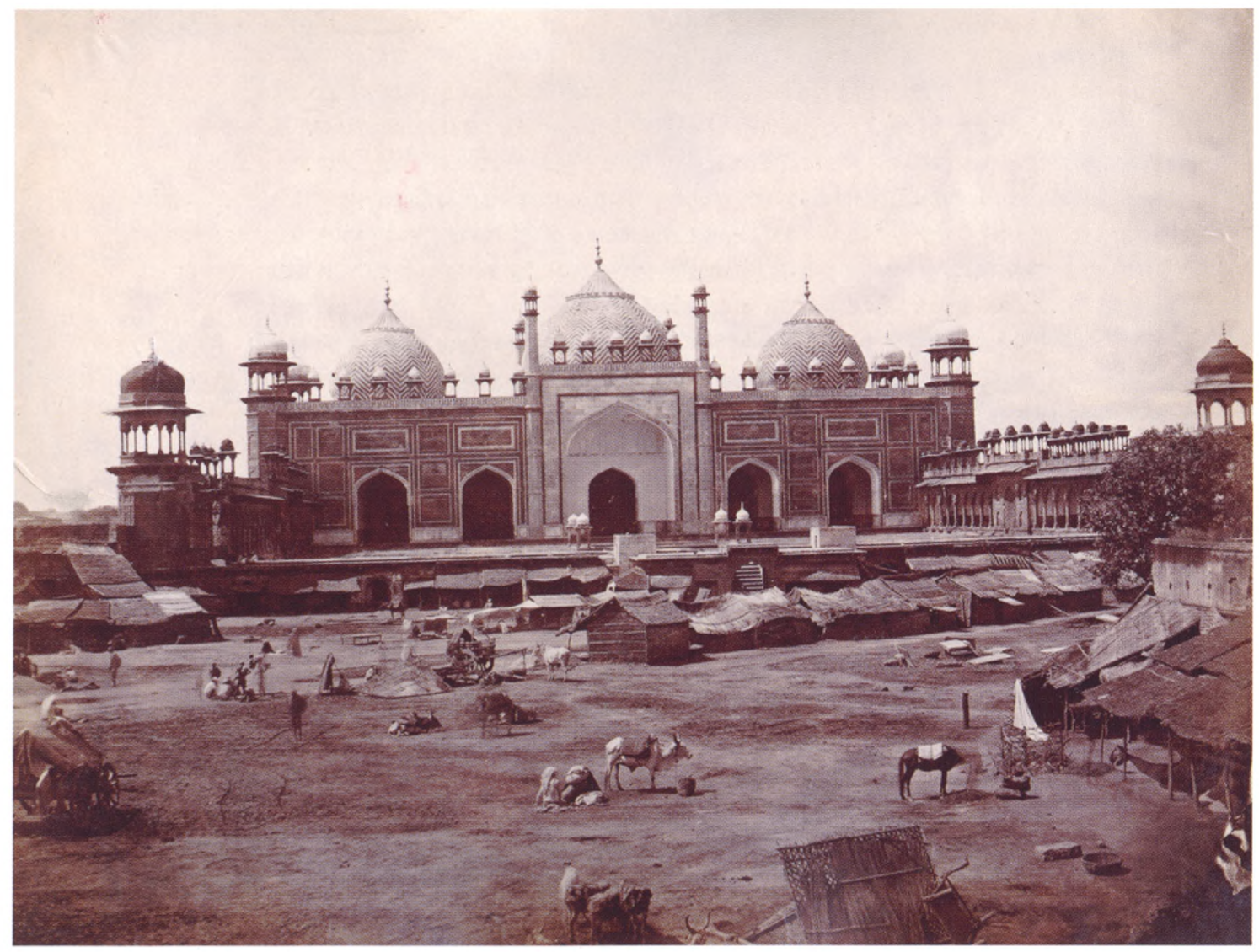

Afbeelding 4 1870-1875. Badshahi Masjid, Agra, India, Mughal-periode. Indian Museum list no. 512, albumineprint, $20 \times 28,5 \mathrm{~cm}$., W. Caney weergegeven. Kwalitatief soortgelijke foto's zijn terug te vinden in het album 'Islamitische kunst', een bundeling van 68 vroege Surveyfoto's uit de vroegere Punjab.

Het tweede voorbeeld is een foto uit het archeologische werk van Lala Din Dayal (1844-1910), een jonge Indiase Jain, die als tekenaar bij de publieke werken zijn loopbaan begon, maar vanaf 1876 in Indore een eigen studio voerde (afb. 5). Zijn foto's bewijzen dat de Survey naast eigen medewerkers voor de fotografie, ook gebruik maakte van commercieel werkende professionals. In 1882-3 legt hij onder leiding van Sir Lepel Griffin verschillende Centraal-Indiase sites op de plaat vast, waaronder als hoogtepunt Sanchi, waar tussen de $2 \mathrm{e}$ eeuw voor en de $2 \mathrm{e}$ eeuw na Chr. vier stupas werden gebouwd, voorzien van schitterend geornamenteerde toegangspoorten. Deze foto's zijn alle terug te vinden in Famous Monuments of Central India. ${ }^{12}$ Dayal heeft echter vooral bekendheid gekregen door zijn portretfoto's van Centraal-Indiase vorsten. ${ }^{13}$ (zie literatuur)

\section{Het Gandhara-album}

Het laATSTE vOORBEeld van vroege Survey-vastlegging is afkomstig uit het zogenaamde Gandhara-album, waarin 250 albumineprints zijn opgenomen die de vroeg-boeddhistische sculptuur en architectuur ( $1 \mathrm{e}-4 \mathrm{e}$ eeuw na Chr.) tot onderwerp hebben. De term Gandhara is ontleend aan de oude geografische aanduiding voor het gebied, overeenkomend met het huidige access 


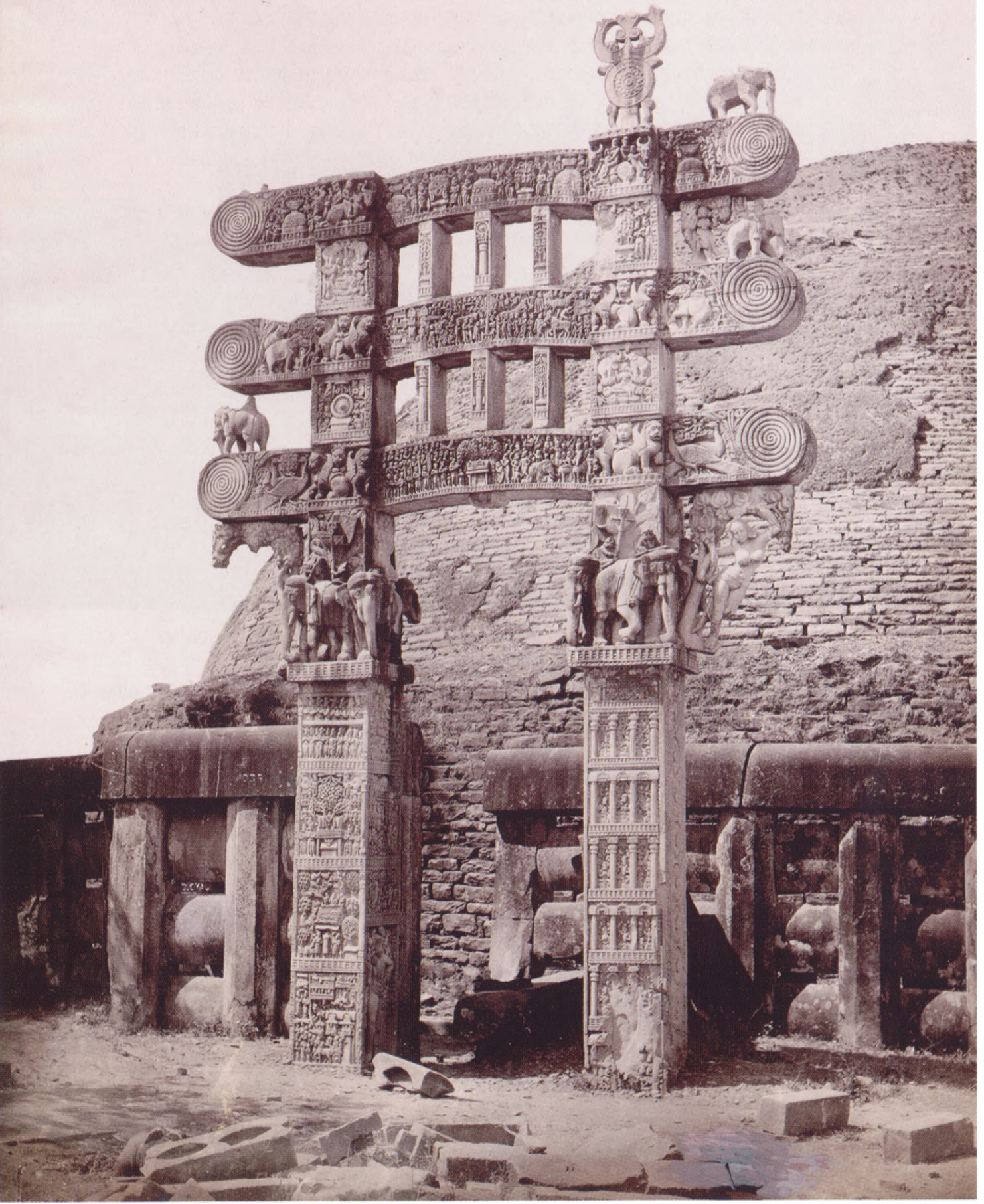


Afbeelding 5 (links) 1881-1883. Oostelijke toegang tot Stupa 1, Sanci, Madhya Pradesh, India, re eeuw.

Herdruk, daglicht gelatine zilverdruk, $29 \times 24 \mathrm{~cm}$., Lala Din Dayal
Afbeelding 6 1872-1873. Bodhisattvas en Kubera, Jamalgarhi, Pakistan, 2e eeuw. Indian Museum List 1900, no. 977, albumine print, 26,5 × $24 \mathrm{~cm}$., J. Craddock

Afbeelding 6a Detail uit afbeelding 6
Noordwest Pakistan. De stijl van de beelden uit dit gebied wordt overeenkomstig als 'Gandhara-stijl' aangeduid. Het album is in Lahore samengesteld en bevat alle in opdracht van de Survey gemaakte foto's uit het vroegere Peshawar district van voor 1885. De foto's blijken van verschillende fotografische hand: de Engelse heren Caddy, Garrick, Major Henry Hardy Cole en de Indiër Beglar. Naast de 200 foto's van in situ boeddhistische kunst of enkelvoudig gepresenteerde sculptuur, bevat het album opvallend veel overzichtsfoto's waarop inhoudelijk gegroepeerde beelden en architectuurfragmenten te zien zijn die niet noodzakelijkerwijs uit één en dezelfde plaats afkomstig zijn: bijvoorbeeld een groep Bodhisattvas bij elkaar (afb. 6), verhalende reliëfs met episoden uit de Boeddhalegende, kapitelen etc. De beelden zijn opgeslagen in houten kratten, hetgeen betekent dat ze vlak voor of na een transport zijn gefotografeerd. Een soortgelijk transport heeft in 1885 plaatsgevonden, waarbij de stukken per stoomboot over de Indusrivier zijn verscheept in opdracht van Director-General Alexander Cunningham. Een deel van de gefotografeerde Gandhara-kunst is overgebracht naar musea in Calcutta, Peshawar en Lahore; een ander deel is verloren gegaan in het scheepstransport naar Londen. Het album is nagenoeg uniek: alleen in de India Office Library in Londen is een identiek album.

\section{Het Nationaal Restauratie Atelier Rotterdam}

Het AlBum ZELF en de foto's bevonden zich in een slechte staat. Doordat de foto's in Lahore met een verkeerde lijmoplossing op een verkeerde papieren drager waren geplakt, hadden ze een sterk gebobbeld oppervlak gekregen. De wisselende temperatuur en vochtigheidsgraad van Lahore hadden er bovendien voor gezorgd dat een groot aantal foto's door schimmel was aangetast. Dankzij de financiële steun van de Stichting Jan Gonda-fonds heeft het Instituut Kern het album ter restauratie aan kunnen bieden bij het Nationaal Fotorestauratie Atelier in Rotterdam. Deze heeft de werkzaamheden recentelijk afgerond. ${ }^{14}$ Daarbij zijn de foto's door indirecte bevochtiging aan de achterzijde voorzichtig losgeweekt van hun schadelijke ondergrond en
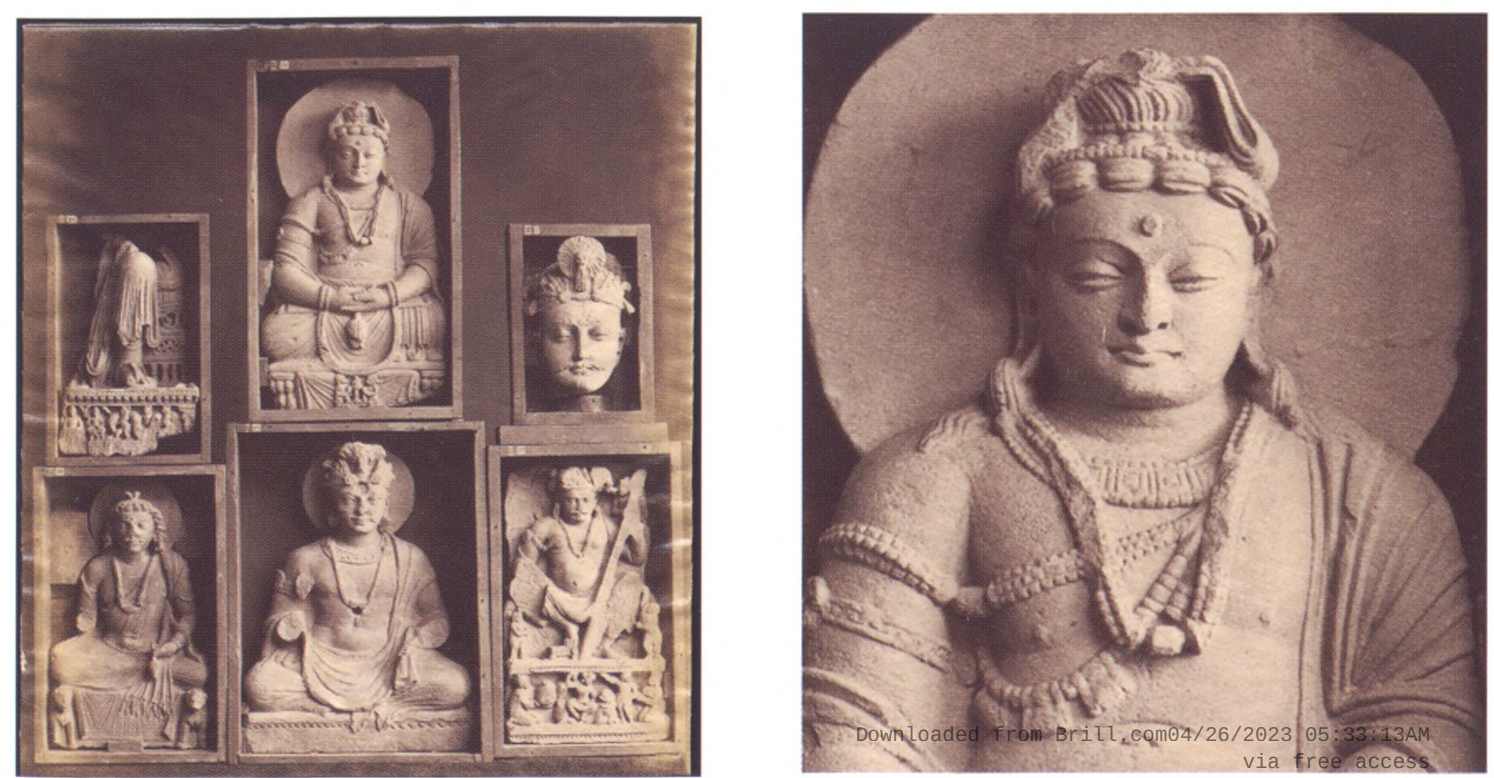


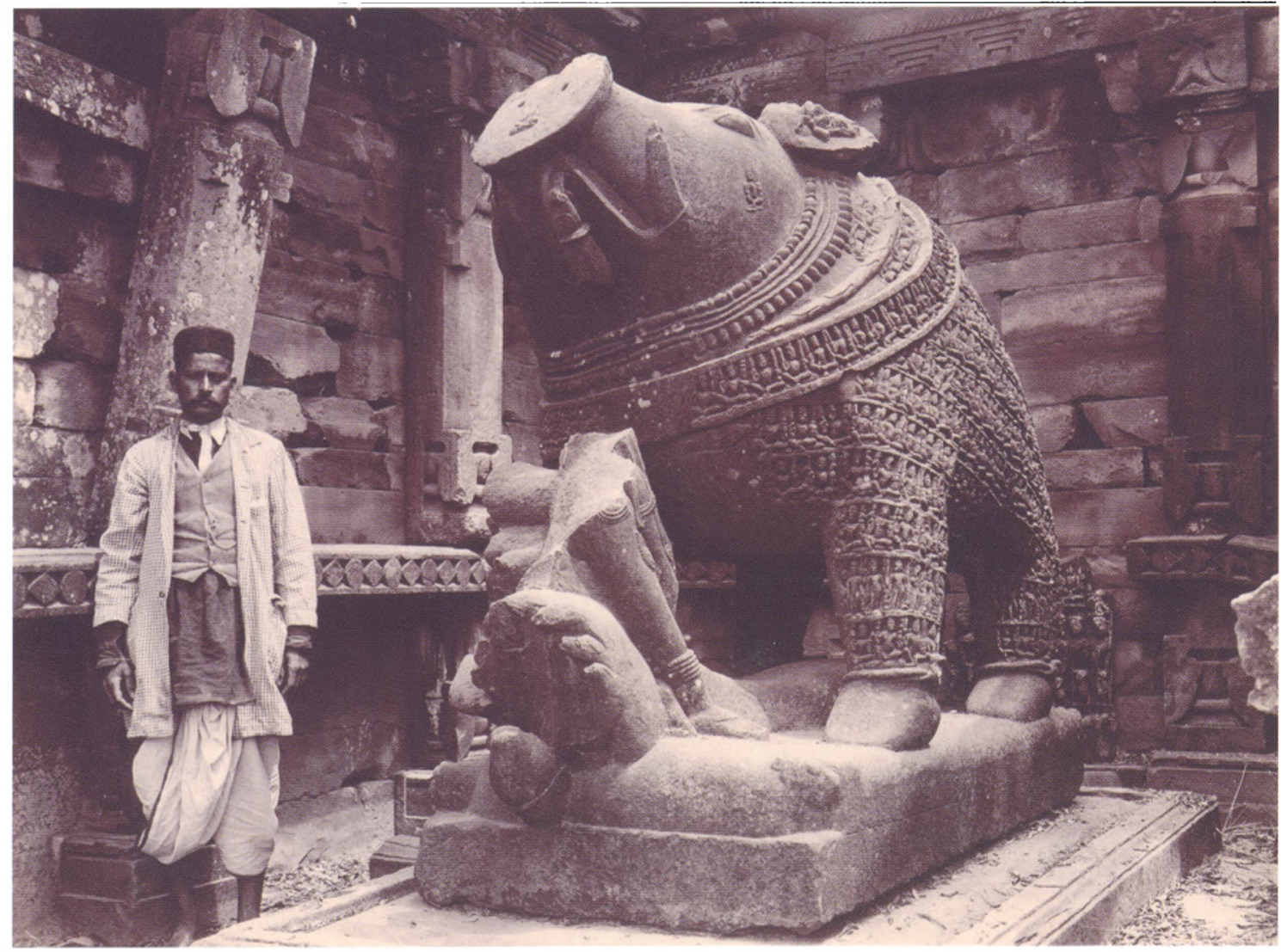

Afbeelding 7 1905-1920. Theriomorfe voorstelling van het kosmische zwijn Varaha, die de godin Aarde (Bhu) uit de wateren opheft, ca. 2,5 m. hoog, Muradpur, Madhya Pradesh, India, 6e-8e eeuw. Daglicht gelatine zilverdruk, $15 \times 20,5 \mathrm{~cm}$., onbekende fotograaf ASI vrijgemaakt van eventuele paginaresten. Een tijdrovende klus, maar geslaagd. De foto's zijn gevlakt en vervolgens hoogwaardig door het Restauratie Atelier gescand. Afbeelding $6 a$ is een sterk vergroot detail uit afbeelding 6 waarmee bewezen is hoe gemakkelijk er details gehaald kunnen worden uit een goede scan. De foto's zijn nu klaar om in een nieuw, identiek ogend album ondergebracht te worden. Hiertoe zijn uitgebreide tests gedaan om na te gaan welke lijmoplossing en methode het meest geschikt is voor hermontage.

\section{De Indian Survey na 1900}

NA CA. 1900 HEBBEN we met een hele andere situatie te doen. Steeds meer voor de ASI werkende tekenaars worden vervangen door fotografen. Al snel wordt de toepassing van de fotografie in de archeologie dusdanig algemeen, dat de naam van de fotograaf verdwijnt uit de korte eenregelige aanduiding van de foto. Ook wordt het de verantwoordelijkheid van de verschillende Survey Circles zelf om negatievenlijsten aan te leggen en deze op te nemen in hun Annual Progress Reports.

Dit betekent niet dat er geen mooie foto's meer zijn gemaakt. Afbeelding 7 is zo'n fotografisch en inhoudelijk juweel. We zien een theriomorphe Varahagestalte, (nu bekend als de 3e avatara van de hindoeïstische god Vishnu) die de aarde opheft. Deze wordt gepersonifieerd weergegeven in de gestalte van de godin Bhu. Als het kosmische everzwijn, is het Varaha's taak om de aarde - symbool van een nieuwe schepping - opnieuw met zijn slagtanden uit de oerwateren op te heffen na een periode van destructie. Helaas is devgestalteaccess 


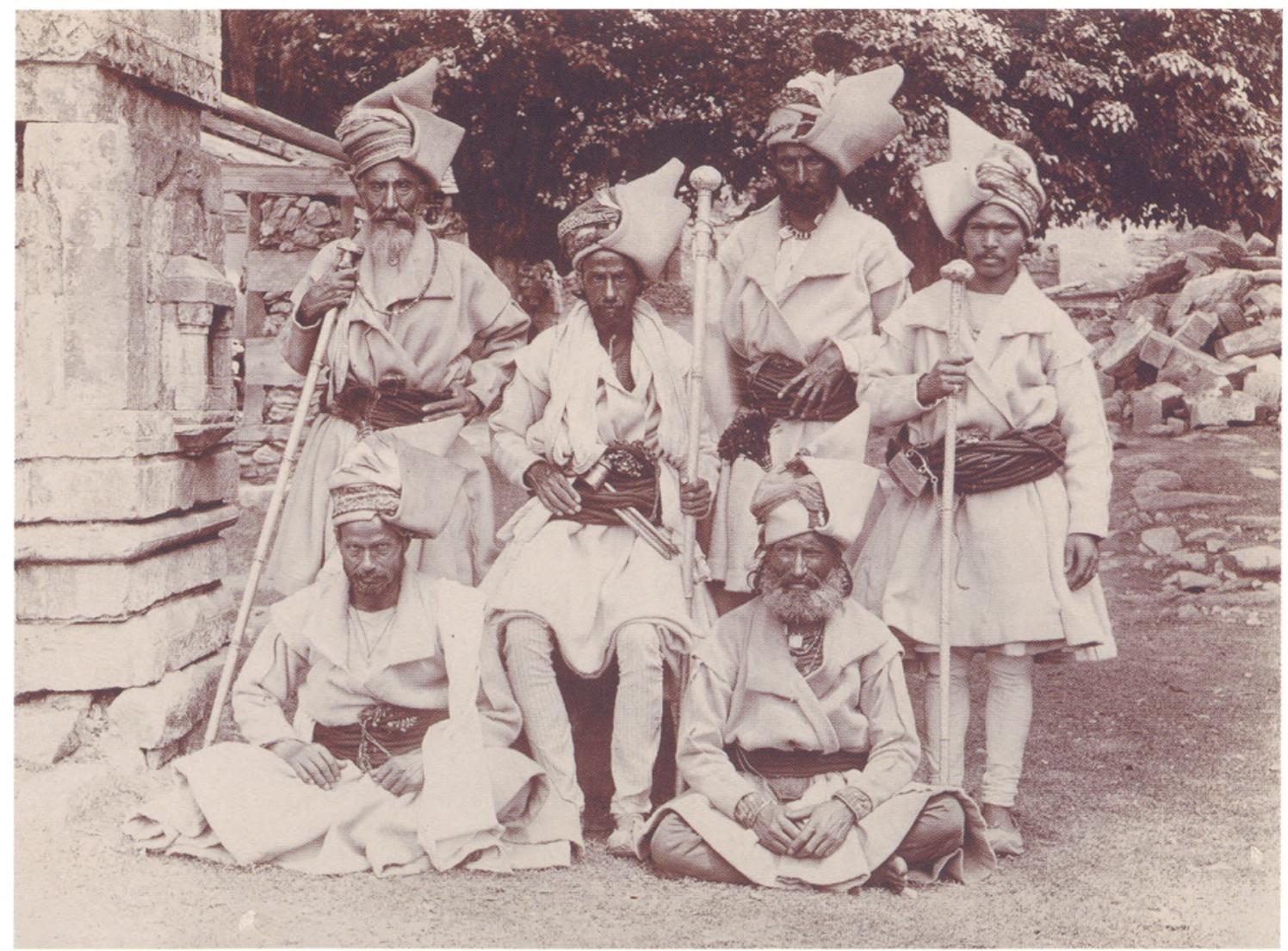

Afbeelding 8 1902-1908. Officials of State in festive dress, Brahmor, Himachal Pradesh, India. ASI, Northern Circle, daglicht gelatine zilverdruk, $15 \times 20,5 \mathrm{~cm}$., Munshi Ghulam Nabi

van Bhu afgebroken, maar het zal u weinig moeite kosten de gestalte af te maken en onder de indruk te komen van deze ca. 2,5 meter hoge kolossus, volledig bedekt met godenseries, hun verschillende manifestaties, zieners en nagas. ${ }^{15}$

Afbeelding 8 toont dat de zogenaamde antropologische archeologie ook in 1908 werd beoefend. Het is een foto van een groep hoogwaardigheidsbekleders, die in Brahmor, een dorp in het vroegere vorstendom Chamba, bijeen zijn om een festival te vieren. De fotograaf is Munshi Ghulam Nabi, een van de vaste fotografen van de 'Northern Circle', waaraan Vogel tussen 19011913 leiding gaf. Chamba was een van zijn favoriete sites: een betrekkelijke white spot op de kaart, met veel archeologisch potentieel. Bovendien, door haar ligging in de Himalaya, een prima plek om de zomerhitte in Lahore te ontspringen.

Alle Circles samen waren goed voor enkele honderden foto's per jaar; een mega-visuele bron dus, van waaruit - dankzij Vogel - tot ca. 1940 ook een mooi, constant stroompje naar Leiden voerde. Hierdoor zijn vele belangrijke sites van de Zuid-Aziatische kunst en archeologie goed gedocumenteerd. Rest nog u te wijzen op de specifieke situatie van Burma (Myanmar), dat sinds 1886 een provincie van Brits India was; Burma was in de ASI vertegenwoordigd met een eigen Circle. De collectie telt 113 foto's.

Voor Sri Lanka lag de situatie anders. Daar functioneerde een zelfstandig opererende Archaeological Survey, waarvan 500 foto's in de Kern-collectie zijn terug te vinden. 
Afbeelding 9 ca. 1910. Ganesha, Candi Banon, Centraal Java, ge eeuw. Oudheidkundige Dienst voor Nederlandsch. Indie, no. 1117b, ontwikkel gelatine zilverdruk, $21 \times 15,5 \mathrm{~cm}$., Leydie Melville

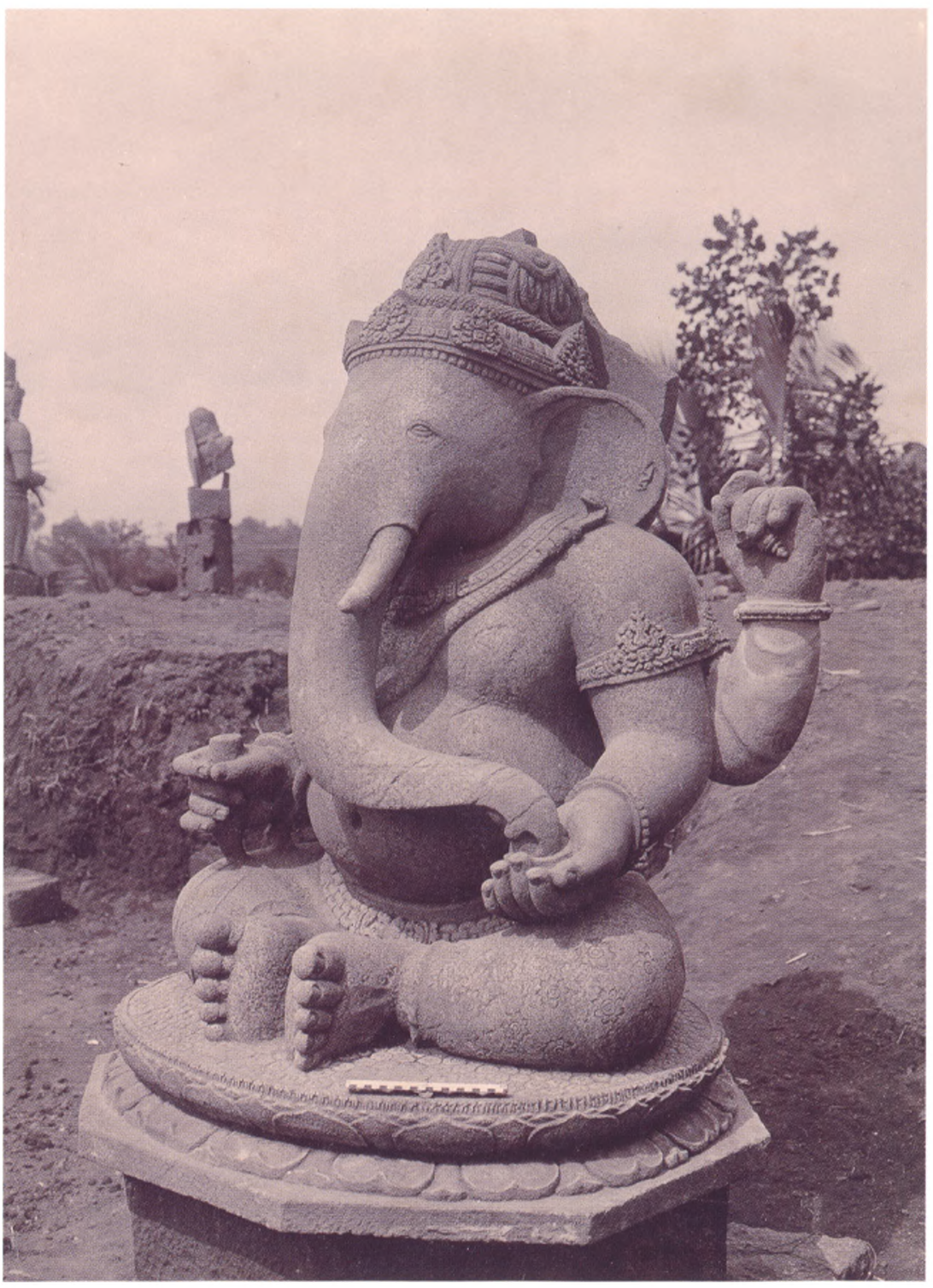

\section{De Oudheidkundige Dienst in Indonesië (1901-1955)}

HOE VERLOPEN DEZE Survey-ontwikkelingen in Nederlands-Indië? Werd de fotografie voor 1900 aangestuurd door locale archeologische verenigingen en het Bataviaasch Genootschap in Batavia, de roep om een centraal gestuurde organisatie voor de Indische monumentenzorg werd steeds duidelijker.

In 1901 wordt daartoe de Oudheidkundige Commissie voor Java en Madoera in het leven geroepen, die in 1913 opging in een nieuwe, breder georiënteerde organisatie: de Oudheidkundige Dienst in Nederlandsch-Indië (de O.D.), met als werkterrein de hele Indische archipel.

Dankzij Krom's inspanningen kan het Instituut Kern al bij de oprichting in access 


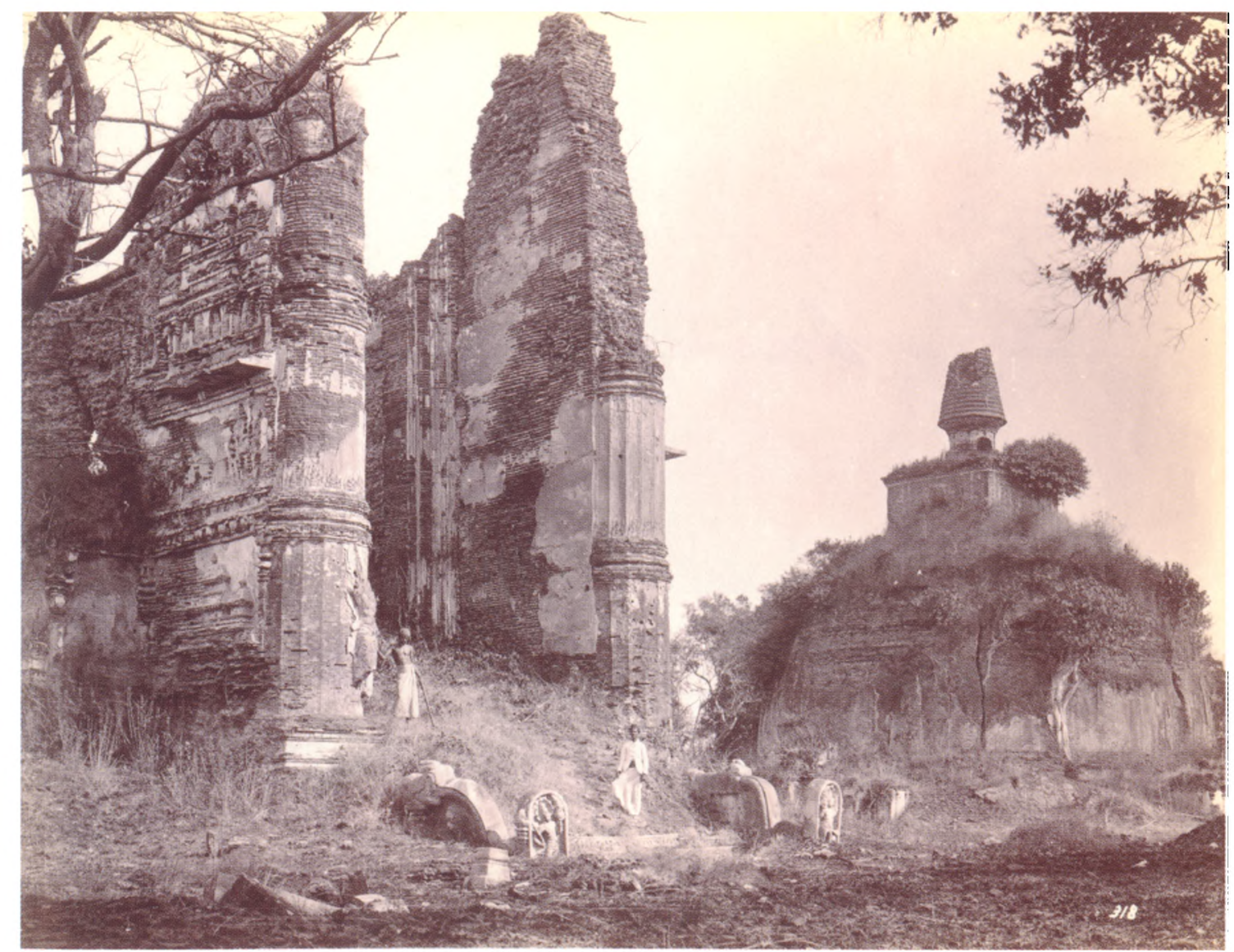

Afbeelding 10 1892-1895. Jetavanarama Temple, Pollonaruva, Sri Lanka. ne-12e eeuw. Skeen \& Co. nr 318, daglicht gelatine zilverdruk, 21 x $27 \mathrm{~cm}$., firmafotograaf april 1925 beschikken over een volledige set foto's (op dat moment ca. 7.000) van de O.D., dankzij een schenking van de toenmalige Minister van Koloniën. Deze collectie zou tot 1955, wanneer het werk van de Oudheidkundige Dienst al verschillende jaren binnen de Indonesische organisatie Dinas Purbakala is voortgezet, op indrukwekkende wijze uitgroeien tot een Leidse collectie van 14.791 foto's. Een fantastisch all Indonesia reservoir voor de bestudering en de geschiedenis van de Indonesische archeologie.

De originelen bevinden zich in de geklimatiseerde kluis van het Instituut Kern. Een schaduwcollectie met nieuwe prints en een zoeksysteem hierop, bevindt zich in de UB van Leiden. Ook is de collectie op microfiche te raadplegen in de bibliotheek van het Instituut Kern. Afbeelding 9, een beeld van de hindoeïstische god Ganesha, zoon van Shiva, is een vroeg voorbeeld uit de collectie.

NIET TOT DE O.D.-collectie behorend, maar wel binnen genoemde periode vallend, is de Theodoor van Erp subcollectie, die de Balinese architectuur tot onderwerp heeft. Van Erp, voormalig Luitenant Kolonel der Genie en leider van de Boroboedoer-restauratie van 1907-1911, had het plan zijn in 1 1925e access 


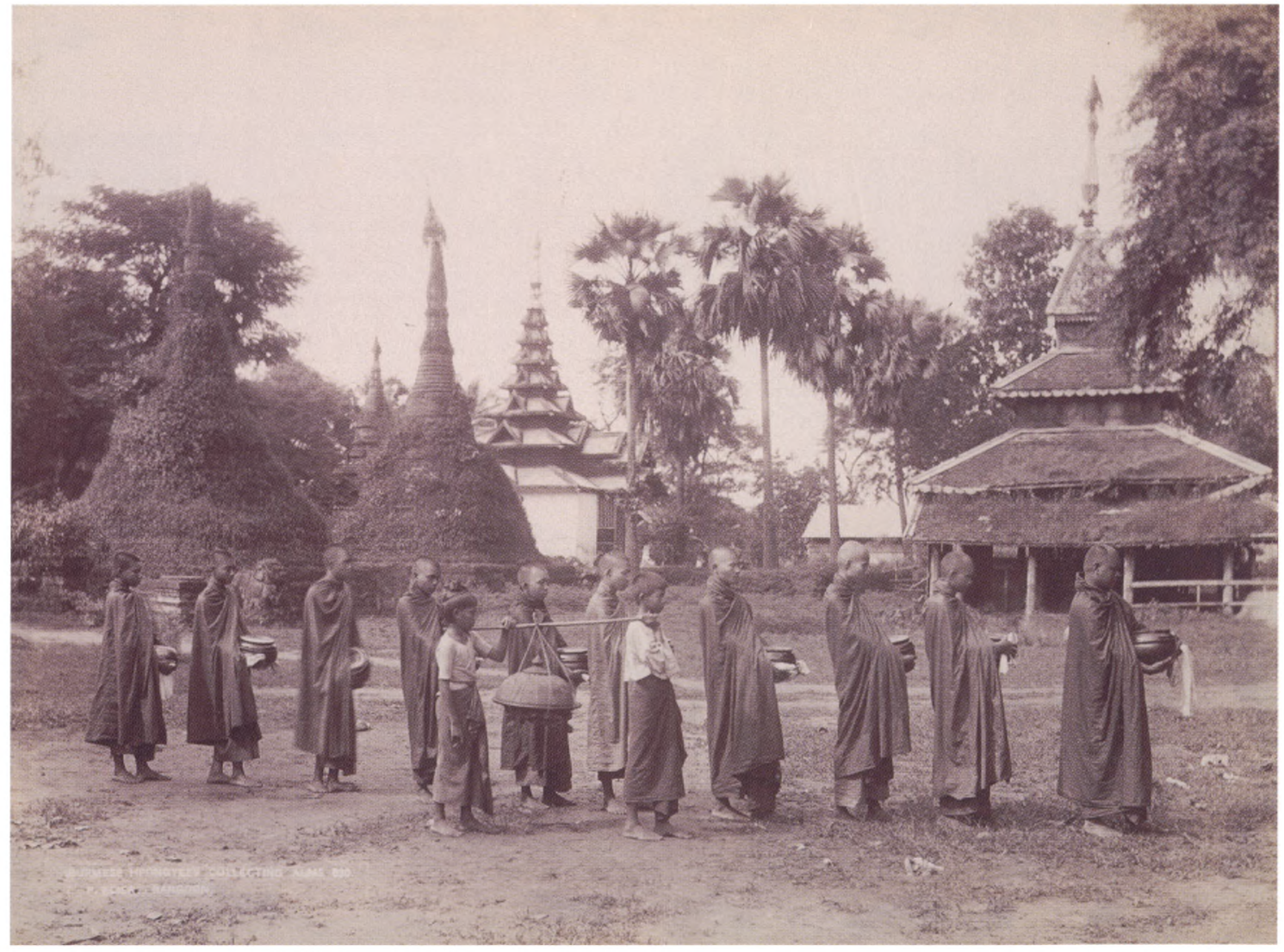

Afbeelding 11 (boven) 1880-1890. Burmese hpyongees collecting alms, no. 590, Yangon, Myanmar.

Albumineprint, $20 \times 27 \mathrm{~cm}$.,

Philip Adolphe Klier

Afbeelding 12

1880-1890. Burmese idol maker, no. 229,

Yangon, Myanmar. Albumineprint, $20 \times 27 \mathrm{~cm}$., Philip Adolphe Klier

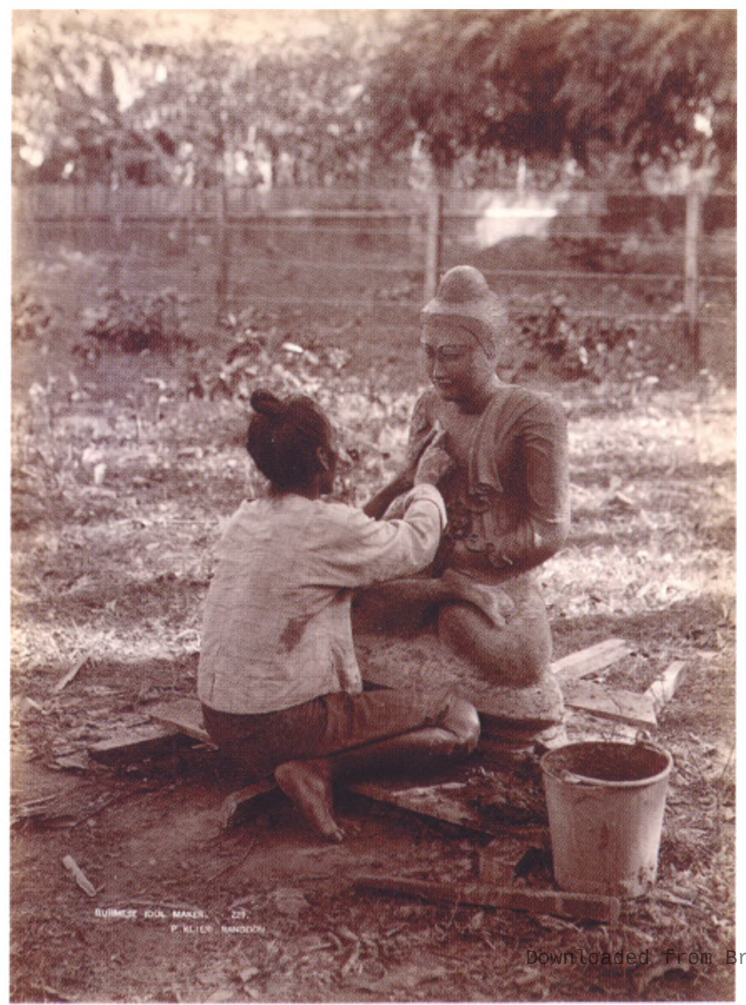


gemaakte foto's in boekvorm uit te geven. Het Bali-boek is er nooit gekomen; de foto's heeft hij het instituut nagelaten.

De 600 foto's tellende collectie zwart-wit foto's van Claire Holt sluit hier chronologisch op aan. Het betreft opnamen uit de jaren dertig, kwalitatief niet constant, maar heel aanvullend op het O.D. materiaal.

\section{Commerciële fotografie}

Met de Stelselmatige aankoop van commercieel werk heeft Prof. Vogel voor mooi aanvullend beeldmateriaal gezorgd. Zijn eigen camerawerk had hem alleen maar teleurstellingen opgeleverd, waardoor hij "het gesukkel met den photographieën" meer dan zat was. Zijn reisbewegingen zijn dus commercieel vastgelegd, keurig in albums, dat wel. Onbewust heeft hij daarmee een bijdrage geleverd aan de geschiedenis van de fotografie in ZuidAzië, want bladerend door de albums passeren alle grote Indiase en Sri Lankese firma's van rond 1900 de revue: Johnston \& Hoffmann, Brajbasi Friend \& Co., Mirza \& Sons, Clifton \& Co., Apothecaries \& Co., Platee LTD en Skeen $\&$ Co. (afb. 10). Stuk voor stuk mooie voorbeelden van de zo gewilde locatie- en stadsfotografie.

Vogel is net te laat voor het bekende fenomeen van de 'typenfotografie', waarin mensen op grond van hun etnologische achtergrond, beroep, kleding of specifieke gebruiken, 'iconografisch' worden geportretteerd tegen een romantisch geschilderde achtergrond, waarbij een aantal toegevoegde objecten het realiteitsgehalte moet verhogen. Deze 'typen' zijn wel terug te vinden in de collectie ansichtkaarten.

Uit de commerciële collectie twee foto's (afb.11 en 12) van Philip Adolph Klier, een Duitse fotograaf die vanaf 1871 een studio heeft in Moulmein, in het vroegere Beneden-Burma en vanaf 1880 in Rangoon (Yangon). ${ }^{16}$

\section{Recentere collectievorming}

NA HET VERTREK van Krom en Vogel blijft de spiegel van het beeldreservoir vrij constant en zijn de toevoegingen relatief klein. De 500 foto's van Gerard Foekema (India) en de meer dan 1.000 foto's van dr. H. Hinzler, docente bij de opleiding Talen en Culturen van Zuidoost-Azië en Oceanië, Leiden, zijn hierop een uitzondering (Centraal- en Oost-Java, Bali)

IN 1995 VERDUBBELDE de foto-collectie in omvang door de uitzonderlijk rijk geschakeerde BAKA-collectie, de foto's van het voormalige Instituut voor Zuid-Aziatische Archeologie in Amsterdam, dat lange tijd door prof. J.E. van Lohuizen-de Leeuw werd geleid. Alle foto's zijn tussen 1950 en ca. 1985 gemaakt, waarbij mevrouw Lohuizen zelf regelmatig de camera hanteerde. Daarbij heeft zij zich niet alleen gericht op de voor de Indische kunst belangrijke sites, maar ook de Aziatische kunst in de musea - van uiterst 'locaal' tot 'mondiaal' - vastgelegd.

Het meeste werk is aangekocht en blijkt gemaakt door professionele tot semiprofessionele fotografen. Als totaal is het een rijke collectie, met een brede geografische spreiding, waarvan de waarde alleen maar zal toenemen.

De toegankelijkheid van deze collectie is deels nog onvoldoende. Een aantal subcollecties licht ik er graag uit.

Allereerst de ruim $\mathbf{8 . 7 7 5}$ foto's van Yves Coffin, een Franse diplomaat in Azië, die al zijn vrije tijd in de fotografie lijkt te hebben gestoken. Zijn foto's van access 
Vietnam, Cambodia en Indonesië kenmerken zich door fotografische kwaliteit en een ongekend oog voor detail; een fantastisch uitgangspunt dus voor onderwijs en wetenschap. Verder zijn er 1.850 foto's van Josephine Powell, een gepassioneerde Amerikaanse fotografe en etnografe die tussen 1950 en 1980 grote, meerjarige fotografische expedities uitvoerde in Noord-Afrika, het Midden-Oosten en West- en Zuid-Azië, waarbij ze zich richtte op architectuur, textiel, nomaden en dorpscultuur. In de BAKA-collectie zijn kunst- en archeologiefoto's te vinden m.b.t. India, Pakistan, Nepal, Uzbekistan en Afghanistan. Met name de foto's van Bamiyan en de collectiestukken van het Kabul Museum stijgen, door de recente politieke ontwikkelingen, ver uit boven hun gemiddelde documentatiewaarde. Ook in de BAKA-collectie is er werk van de fotograaf Gerard Foekema te vinden. Het betreft ruim 2.000 in situ opnamen in India en Myanmar.

\section{Naar een digitale ontsluiting}

VELE VAN DE door Krom en Vogel samengebrachte foto's zijn nu 75-100 jaar oud en soms zelfs 130 jaar. De groei van de collectie door de decennia heen en de beperkte zorg die er door een constant gebrek aan mankracht aan gegeven kon worden, had het fotobezit complex gemaakt. Er was weinig eenheid in de fysieke zorg, er bestonden meerdere beschrijvingssystemen naast elkaar en het niveau van beschrijven verschilde sterk. Kortom het werd tijd voor een stevig Plan van Aanpak. Dankzij de financiële steun uit het Programma Behoud Universitaire Collecties (Ministerie van OC $8 W$ ) kon de achterstand in de conservering worden weggewerkt. Dit betekent dat er in de periode 1999-2001, 42.000 foto's individueel zijn overgedaan in een polyester doorzichthoes; deze werden horizontaal opgeslagen in kartonnen dozen (volgens Photographic Activity Testnorm) om vervolgens overgebracht te worden naar de geklimatiseerde kluisruimte van het Instituut.

Tegelijkertijd maakte een subsidie van de Stichting Jan Gonda-fonds het mogelijk om een specifieke fotodatabase te laten ontwikkelen door het NIWI en de oudste 10.000 foto's te digitaliseren. Er werd gekoerst op een digitale ontsluiting van ca. 40.000 foto's in 3,5 jaar, hetgeen niet haalbaar bleek. Tot op heden zijn er een kleine 25.000 digitaal ontsloten.

De Engelstalige database heeft een thesaurus-, een invoer- en een zoekmodule. De invoermodule heeft 31 beschijvingsvelden om administratieve, fototechnische en vakinhoudelijke gegevens onder te brengen. De zoekmodule makkt het voor $u$ als gebruiker mogelijk deze gegevens te doorzoeken door middel van een enkelvoudige of gecombineerde zoekvraag.

De database is vooralsnog alleen in de bibliotheek van het Instituut Kern te raadplegen, waarbij een eenvoudige handleiding $\mathrm{u}$ op weg helpt. Originelen mogen nog steeds worden bekeken, maar moeten wegens personeelsgebrek een dag van tevoren worden aangevraagd. Er wordt momenteel druk gewerkt aan een internetontsluiting voor de collectie, die dit najaar door de UL gerealiseerd moet zijn.

Ik houd u graag op de hoogte, vooralsnog bent u fysiek van harte welkom in de Kern-bibliotheek. 


\section{Literatuur}

V. Dehedija (red.), India through the lens, photography 1840-1911, Washington D.C., 2000.

U. Pohlmann, et.al., Samuel Bourne. Sieben Jahre Indien, Photographien und Reiseberichte 1863-1870, München, 2000.

J. Falconer, A Shifting Focus: Photography in India, 1850-1900, London, 1995.

G. Knaap, Cephas, Photography in the service of the sultan, Leiden, 1999.

S. Merrillees, Batavia in nineteenth century photographs, Richmond, Surrey, 2001.

J. Levy Reed (red.), Toward independence. A Century of Indonesia Photographed, San Francisco, 1991.

S. Wachlin, Woodbury and Page photographers Java, Leiden, 1994.

C. Worswick \& E. Ainslee, The Last Empire: Photography in British India, 1855-1911 Millerton, N. Y., 1976.

C. Worswick, Princely India: Photographs by Raja Lala Deen Dayal, Court Photographer (1884-1910) to the premier Prince of India, New York, 1980.

\section{Noten}

1. Kunsthistorica Zuid- en Zuidoost-Azië en manager van de Fotocollectie van het Instituut Kern.

2. Brief J.Ph. Vogel aan zijn vader, dd 15 november 1905. Archief Vogel, doos 37, Instituut Kern, Leiden.

3. Brief J.Ph. Vogel aan zijn vader, dd 21 augustus 1910. Archief Vogel, doos 37, Instituut Kern, Leiden.

4. A. Groeneveld, et.al., Toekang Potret, 100 jaar fotografie in Nederlands Indië, Amsterdam, 1989.

5. www.kitlv.nl; www.earlyphotography.nl; www.bl.uk/collections/asipho.html.

6. G. Theuns-de Boer, 'Java through the eyes of van Kinsbergen', in: IIAS Newsletter 27 (2002), p. 32.

7. S. Bourne, 'Narrative of a Photographic trip to Kashmir and adjacent districts', in: British Journal of Photography (January 4, 1867), p. 4.

8. W. B. Woodbury. 'Photography in Java; Account of a short photographic ramble through the interior of the east end of the island', in: The Photographic News 5-128 (February 15, 1861), pp. 78-79; 5-129 (February 22, 1861), pp. 91-92; 5-132 (March $15,1861)$, pp. 126-127.

9. Bestuursvergadering 13 februari 1872. Notulen van de Algemeene en Bestuursvergaderingen van het Bataviaasch Genootschap, Batavia, 1873.

10. D.K. Chakrabarti, A History of Indian Archaeology, from the beginning to 1947, Delhi, 1988.

11. T. Bloch, A list of the photographic negatives of Indian Antiquities in the collection of the Indian Museum with which is incorporated the list of similar negatives in the possession of the India Office, Calcutta, 1900.

12. Famous Monuments of Central India, London, 1886.

13. Zie Literatuur, onder Worswick.

14. Montage van kwetsbare albuminefoto's. Uitgebreid onderzoek cum laude afgerond in: Nederlands Fotogenootschap Nieuwsbrief 33 (augustus 2001), pp. 12-13.

15. G. Theuns-de Boer, 'The boar as an image of creation', in: IIAS Newsletter 26 (2001), p. 22.

16. G. Theuns-de Boer, 'Collecting alms as a character of Burmese Life', in: IIAS Newsletter 21 (2000), p. 24. 